\title{
Pneumocystis jirovecii detection and genotyping from HIV-positive and HIV-negative Mexican patient samples
}

\author{
Amanda Alcántara-Mojica, ${ }^{1}$ Laurence Delhaes, ${ }^{2}$ Fabiola Ramírez-Corona, ${ }^{3}$ Edith Sánchez-Paredes, ${ }^{1}$ \\ Érika Córdova-Martínez, ${ }^{1}$ Fernando Rosalío Morales-Villarreal, ${ }^{4}$ Sigfrido Sierra-Galván ${ }^{3}$ and \\ Francisca Hernández-Hernández ${ }^{1 *}$
}

${ }^{1}$ Universidad Nacional Autónoma de México, Faculty of Medicine, Department of Microbiology and Parasitology, Mexico City, Mexico; ${ }^{2}$ University of Bordeaux, Faculty of Medicine, Bordeaux, France; ${ }^{3}$ Universidad Nacional Autónoma de México, Faculty of Sciences, Mexico City, Mexico; ${ }^{M}$ Ministry of Health, National Institute of Respiratory Diseases, Mexico City, Mexico

\begin{abstract}
Introduction: Pneumocystis jirovecii is an atypical fungus particularly detected in HIV-positive or transplanted patients. Objective: To detect and genotype Pneumocystis jirovecii in patient samples from two hospitals in Mexico É ity. Method: Eighty-nine respiratory tract samples, corresponding to 53 patients (30 HIV-positive and 23 HIV-negative) with respiratory symptoms and to 11 healthy individuals included as negative control, were processed. DNA was extracted and amplified by nested polymerase chain reaction from the internal transcribed spacer, with one fragment being obtained at each round (693 and 550 bp). Genotypes and their phylogenetic relationship were determined by sequencing the 550 bp fragment. Results: Forty-eight samples from 30 HIV-positive patients were received from a single hospital, out of which 11 (36.6) \%) were positive for Pneumocystis jirovecii. No sample was positive in HIV-negative patients or healthy subjects. The mostfrequently detected haplotypes were Eg and Em. Conclusions: The frequency of Pneumocystis jirovecii infection was high in the studied Mexican population. The most common genotype was different from those reported in other countries. It is necessary to address this health problem through early detection of this infection.
\end{abstract}

KEY WORDS: Pneumocystis jirovecii. Pneumonia. Human immunodeficiency virus. Mycosis.

\section{Introduction}

Pneumocystis jirovecii is an opportunistic fungus whose in vitro culture has not been achieved. It causes pulmonary infection in immunocompromised individuals, particularly in those infected with the human immunodeficiency virus (HIV) who have developed acquired immunodeficiency syndrome (AIDS), who are malnourished or have undergone transplants. ${ }^{1}$ Pneumocystis jirovecii is acquired via the respiratory tract at early stages in life and often it is found as a commensal in immunocompetent individuals. During immunosuppression, the microorganism multiplies in the alveoli, inducing an inflammatory proces. ${ }^{2}$ Pneumocystis jirovecii pneumonia (PCP) is manifested by nonspecific symptoms, although respiratory failure is the most common complication and is associated with elevated mortality. ${ }^{3}$

To detect Pneumocystis jirovecii, stains (Gomori-Grocott and Giemsa) and molecular procedures are commonly used. ${ }^{4,5}$ Polymerase chain reaction (PCR) has been commonly directed towards ribosomal DNAinter-transcriber spacer (ITS) region. ${ }^{2,6}$ This ITS region is the "barcode" to identify the fungus. The comparison of ITS region sequences is widely used in molecullar taxonomy and phylogeny because it is very easy to
Correspondence:

*Francisca Hernández-Hernández

E-mail: frank-hh@comunidad.unam.mx
Date of reception: 10-09-2018

Date of acceptance: 02-05-2019

DOI: 10.24875/GMM.M19000301 
amplify, even with small amounts of DNA, and has a high degree of variation, even between tightly close species. This marker exists in multiple copies in most fungal cells and is retrievable with relatively robust oligonucleotides with a high degree of reliability. ${ }^{7,8}$

For each target gene, type-sequences have been reported, and differences detected in similar studies have determined numerous genotypes..$^{2,9,10}$ For the ITS1 region, more than 30 genotypes are known, and for ITS2, over 40.11

Globally, PCP represents the first or second most common opportunistic infection in patients with HIV infection..$^{12}$ In Mexico, it has been reported in up to $51-55 \%$ of HIV infection cases, and its diagnosis has been based on stains. ${ }^{13,14}$ The purpose of this investigation was to determine the frequency of Pneumocystis jirovecii and its genotypes in samples of HIV-infected/AIDS patients or with any other immunosuppressive pathology, by means of nested PCR of the ITS region followed by sequencing.

\section{Method}

This was a prospective, cross-sectional, prolective study. Respiratory specimens from hospitalized patients with pulmonary symptoms at the National Institute of Respiratory Diseases and the "General Ignacio Zaragoza" Regional Hospital of the Institute of Social Security and Services of State Workers, Mexico City were requested.

Hospitalized patients of any age, of either gender, with respiratory symptoms, without anti-Pneumocystis treatment were included. Informed consent was not requested because the study was carried out with part of the sample obtained for other analyses. Negative control included oropharyngeal washing fluid from healthy subjects, after informed consent was obtained.

For the DNA extraction, the conditions described by Lu et al. ${ }^{15}$ were considered and the High Pure PCR Template Preparation ${ }^{\circledR}$ kit (Roche, Germany) was used. The DNA was stored at $-20^{\circ} \mathrm{C}$ and then used for PCR.

\section{Nested PCR}

- First round: $20 \mu \mathrm{L}$ of DNA was used in a final volume of $50 \mu \mathrm{L}$ containing $1 \mathrm{x}$ of PCR-buffer, $1.5 \mathrm{mM} \mathrm{MgCl}, 1.0 \mathrm{mM}$ deoxyribonucleotide triphosphate, $0.2 \mu \mathrm{M}$ oligonucleotide 1724F (AAG TTG GTC AAA TTT GGT C), $0.2 \mu \mathrm{M}$ oligonucleotide ITS2R (CTC GGA CGA GGA TCC TCG
CC), $1.25 \cup$ Taq DNA polymerase (Invitrogen, Carlsbad, California, USA). Temperature: $94^{\circ} \mathrm{C}$, 5 minutes; 35 cycles at $94{ }^{\circ} \mathrm{C}$ for one minute, $47{ }^{\circ} \mathrm{C}$ for one minute and $72^{\circ} \mathrm{C}$ for two minutes; finally, at $72{ }^{\circ} \mathrm{C}$ for five minutes. The expected product size was 693 base pairs (bp)..$^{15} \mathrm{As}$ negative PCR control, $20 \mu \mathrm{L}$ of sterile miliQ waterand as positive control, $3 \mu \mathrm{L}$ of DNA from a sample markedly positive for Pneumocystis jirovecti by Gomori-Grocott staining and by PCR were used.

- Second round: $2 \mu \mathrm{L}$ of the first round amplification product was used, at a final volume $50 \mu \mathrm{L}$. The oligonucleotides were ITS1F (CGT AGG TGA ACC TGC GGA AGG ATC) and ITS2R1 (GTT CAG CGG GTG ATC CTG CCT G). Concentrations of the reaction mixture were similar to those of the first round. Temperatures: $94{ }^{\circ} \mathrm{C}, 10$ minutes; 35 cycles at $94^{\circ} \mathrm{C}$ for one minute, $58{ }^{\circ} \mathrm{C}$ - for one minute, $72{ }^{\circ} \mathrm{C}$ for minutes. A final extension was applied at $72{ }^{\circ} \mathrm{C}$ for 10 minutes. The expected product size was $550 \mathrm{bp} .^{15}$

Amplicons were run on $1.5 \%$ agarose gel, stäined with ethidium bromide, purified and sent for sequencing to the Institute of Biology of the National Autonomous University of Mexico, Mexico City, Mexico, with the chain-termination inhibition method. ${ }^{16}$ All sequences were carried out in duplicate in $5^{\prime}-3$ ' and ' $3{ }^{\prime}-5$ ' directions.

\section{Sequence analysis}

Sense and antisense sequences were analyzed and edited with the ChromasPro program and compared with three databases: Basic Local Alignment GenBank Search Tool (https://www.ncbi.nlm.nih.gov/), The European Molecular Biology Laboratory (http://www. embl.de/) and Kyoto Encyclopedia of Genes and Genomes (http://www.genome.jp/kegg/).

The sequences were also analyzed with the MEGA program, version 6.0 , to build a phylogenetic tree with the neighbor-joining method, using the two-parameter Kimura model with a 1000-repetition bootstrap. ${ }^{7}$ Multiple alignment was carried out using ClustalW. A matrix of genetic distances was constructed.

\section{Genotype determination}

The sequences reported by Lee et al., ${ }^{9}$ who considered 15 genotypes for the ITS1 region (A-O) and 14 genotypes for ITS2 (a-n) were taken as reference. 


\section{Results}

Forty-eight samples from 30 patients $(23$ males and 7 females) were received from the National Institute of Respiratory Diseases. Age ranged from five to 76 years, with an average of 35.7. Most samples (30) were bronchoalveolar lavage fluid and tissue (18). In 26 patients (86.6\%), the main opportunism factor was HIV/AIDS infection, most of them confirmed (Table 1).

Thirty samples, corresponding to 23 patients (15 males and eight females), were received from the "General Ignacio Zaragoza" Regional Hospital. Age ranged from one to 86 years, with an average of 50.6. Most samples (25) were sputum. Patients had various opportunism factors, predominantly pulmonary tuberculosis (seven, $29.16 \%$ ), which was probable or confirmed the time of sample reception (Table 2).

The negative control group consisted of 11 oropharyngeal lavage fluid samples from healthy adults, whose average age was 34.2 years, without history of smoking or respiratory symptoms at the moment of sampling.

\section{Pneumocystis jirovecii detection}

Figure 1 shows the parasitic structures stained with Gomori-Grocott and the amplicon corresponding to Pneumocystis jirovecii obtained from bronchoalveolar lavage fluid, which was used as a positive PCR control. The fragment was purified and sequenced to corroborate its identity with Pneumocystis jirovecii.

Of the 30 patients from the National Institute of Respiratory Diseases, 11 were Pneumocystis jirovecii-positive (Figures $1 \mathrm{~B}$ and $2 \mathrm{~A}$ ), all of them had HIV infection as opportunism factor, nine were males and two females. In five patients, PCP had been previously diagnosed by Gomori-Grocott staining, and all were confirmed by PCR. Pneumocystis jirovecii-positive patients accounted for $36.6 \%$ of cases at this institution.

In sample 12a, which corresponded to a patient of the National Institute of Respiratory Diseases, a 620bp amplicon of was obtained, which is larger than the expected size (Figure 2B). This fragment was sequenced and analyzed.

All samples from the "General Ignacio Zaragoza" Regional Hospital and from the negative control group (healthy individuals) were negative for Pneumocystis jirovecii.

\section{Sequence similarity analysis}

Identity with Pneumocystis jirovecii ranged from 90 to $100 \%$. The analysis in all three databases was similar. All amplified fragments corresponded to Preumocystis jirovecii ITS region. In sample 12a, electropherogram was highly reliable and the comparative analysis indicated $87 \%$ identity with Cryptococcussp.

With the sequencing data, a genetic distance matrix was constructed (data not shown), and correlations were explored by analyzing the origin of the samples (Fig. 3). Sample 12a remained on a separate branch with regard to the others. Samples 11 a and $11 \mathrm{~b}$ corresponded to the same patient, whose genetic distance value was 0.000 ; both were grouped in the same branch, which indicates that it is the same Pneumocystis jirovecii strain. Samples 10a and $10 \mathrm{~b}$ also belonged to a single patient, with a genetic distance of 0.152 , and were grouped into different phylogenetic branches, which suggested there was a difference between the Pneumocystis jirovecii strains.

\section{Genotype determination}

Of the 14 Pneumocystis jirovecii-positive samples, in 11 the genotype was determined in both directions. In three sequences, determining the genotype wasnot possible due to the large number of insertions and deletions. In these samples, the procedure was repeated twice more, from DNA extraction to sequence analysis, and the results were similar. For IfS1, genotype $E$ was predominant (seven samples) anđ for ITS2, genotype $g$ (five samples). The predominant haplotypes were Em (four cases) and Eg (three cases). In samples 10a and 10b, which corresponded to a single patient, the genotypes were different. In samples 11a and 11b, which also corresponded to a single patient, the same genotype was found.

\section{Discussion}

Due to the impossibility to retrieve Pneumocystis jirovecii in cultures, molecular procedures have been particularly useful for detecting this organism in samples of patients in whom PCP is suspected. The frequency of Pneumocystis jirovecii detection reported by other authors is variable, depending on various factors such as the type of sample, fungal load, the molecular procedure used and the selected target gene. Nested 


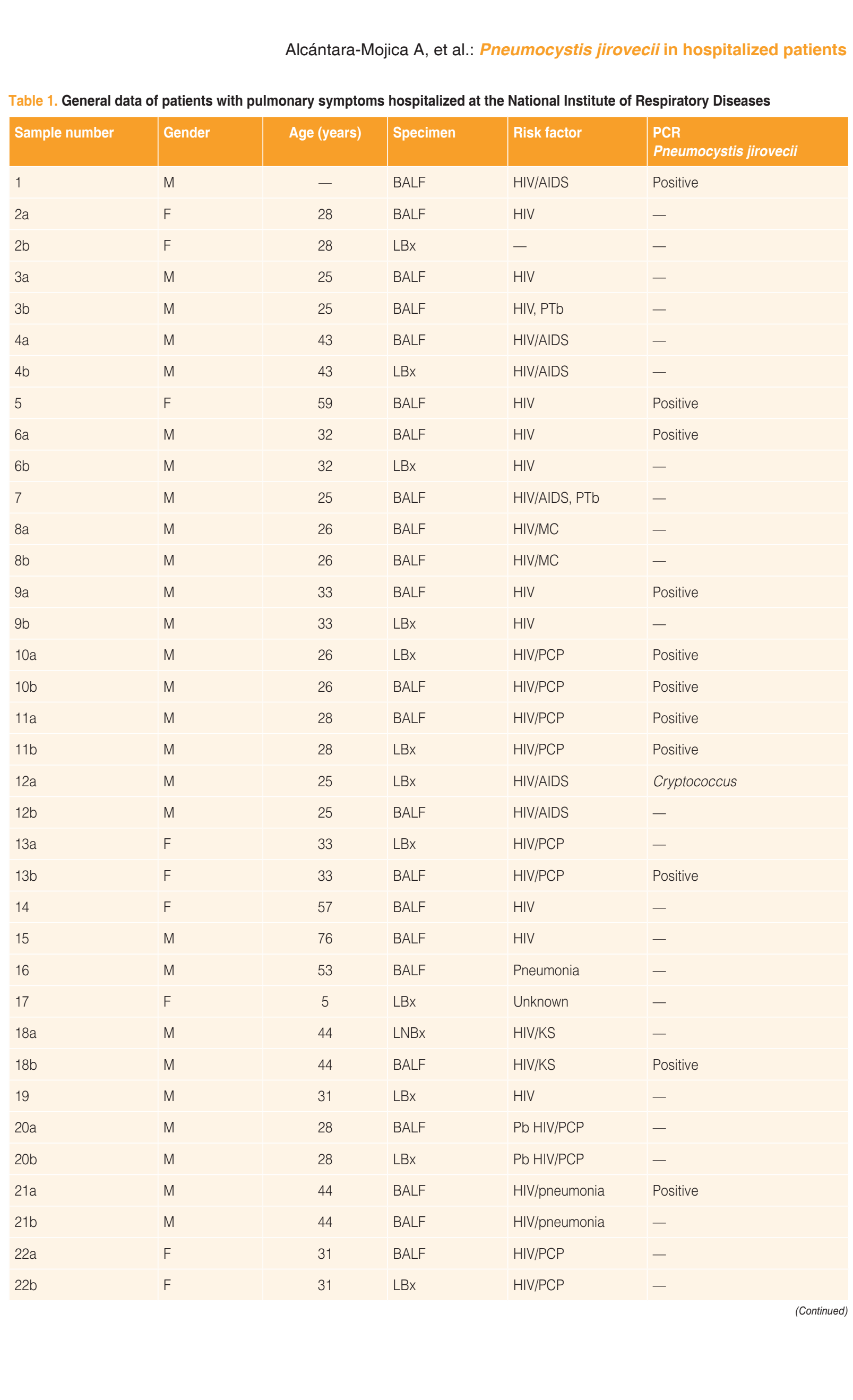


Table 1. General data of patients with pulmonary symptoms hospitalized at the National Institute of Respiratory Diseases (Continued)

\begin{tabular}{|c|c|c|c|c|c|}
\hline Sample number & Gender & Age (years) & Specimen & Risk factor & $\begin{array}{l}\text { PCR } \\
\text { Pneumocystis jiroveci }\end{array}$ \\
\hline $23 a$ & M & 20 & BALF & $\mathrm{Pb} \mathrm{HIV}$ & - \\
\hline $23 b$ & M & 20 & LBx & $\mathrm{Pb} \mathrm{HIV}$ & - \\
\hline $24 a$ & M & 32 & LBX & HIV, LNTb & - \\
\hline $24 b$ & M & 32 & BALF & HIV, LNTb & - \\
\hline 25 & M & 24 & BALF & HIV/PCP & Positive \\
\hline 26 & M & 37 & BALF & HIV/PCP & Positive \\
\hline 27 & M & 31 & LBx & HIV/Pb PTb & - \\
\hline 28 & $\mathrm{~F}$ & 25 & BALF & PCP & - \\
\hline 29 & M & 74 & BALF & $\mathrm{Pb}$ IPF & - \\
\hline $30 a$ & M & 42 & BALF & HIV/PTb & - \\
\hline $30 \mathrm{~b}$ & M & 42 & LNBX & HIV & - \\
\hline $30 c$ & M & 42 & LBx & HIV/PTb & - \\
\hline
\end{tabular}

PCR and real-time PCR using mitochondrial DNA fragments, ITS1 and ITS2 as target genes have shown high sensitivity and specificity values. ${ }^{2,18}$

PCR has revealed sensitivity and specificity values for bronchioalveolar lavage fluid ranging between 84 and $100 \%$ and 58 and $100 \%$, respectively, ${ }^{19.20}$ which is why it has been the most commonly used and reliable specimen. Gupta et al. ${ }^{21}$ studied 180 samples of immunosuppressed patients with clinical suspicion of PCP; using nested PCR directed to the ITS region they found $24.69 \%$ positivity in 81 bronchoalveolar lavage fluid samples and in $12 \%$ of 50 sputum samples. In other countries, such as Brazil, $44.8 \%$ positivity for Pneumocystis jirovecii has been identified by nested PCR in HIV-positive patients. ${ }^{22}$ In this study, out of 30 bronchoalveolar lavage fluid processed samples, 11 (36.6\%) were positive.

The 25 sputum samples that corresponded to patients of the "General Ignacio Zaragoza" Regional Hospital were negative for Pneumocystis jirovecii. In other investigations, negative results have been attributed to the presence of PCR inhibitors..$^{23}$ In the case of the patient group of that hospital, it is possible that other factors could have influenced on negative results, such as a lower degree of immunosuppression caused by the underlying disease, which was mainly pulmonary tuberculosis, occasionally reported in coinfection with Pneumocystis jirovecii. ${ }^{24}$ In this study, the two HIV-positive patients of the "General Ignacio Zaragoza"
Regional Hospital showed no evidence of Pneumocystis, probably due to an immunosuppression moderate stage, such as the cases of pulmonary tuberculosis.

Medrano et al. ${ }^{25}$ detected Pneumocystis jirovecii DNA in $12(20 \%)$ of 50 oropharyngeal lavage fluid samples from healthy individuals, and Vargas et aj, 26 in $32 \%$ of 74 healthy children. In this work, the absence of Pneumocystis jirovecii in healthy individurals possibly occurred because the subjects were onot Pneumocystis jirovecii carriers, because fungal toad was too low or the oropharyngeal lavage procedure was inadequate to detect to the microorganism.

In recent years, genetic databases have exponentially grown and currently there is more information on miecroorganisms' identity. The analysis of the oligonucleotides herein used with the Basic Local Alignment Search dool (BLASTn) indicates that they amplify for one Pneumocystis jirovecii and one Cryptococcus sp DNA fragment. Amplification of a fragment corresponding to Cryptocococcus can be explained because the oligonucleotides described for the ITS region are universal for fungal 'species' molecular identification. ${ }^{7,8}$ In addition, it is-not surprising to find Cryptococcus colonizing or infecting patients with HIV infection, since this yeast (mainly Cryptococcus neoformans) is acquired via the respiratory tract, initially infecting the lung and then invading the central nervous system and other tissues. ${ }^{27} \frac{t}{\sigma}$

Pneumocystis jirovecii genotype mixture (as in samples $10 \mathrm{a}$ and $10 \mathrm{~b}$ ) is a common condition. ${ }^{28}$ It is possible 


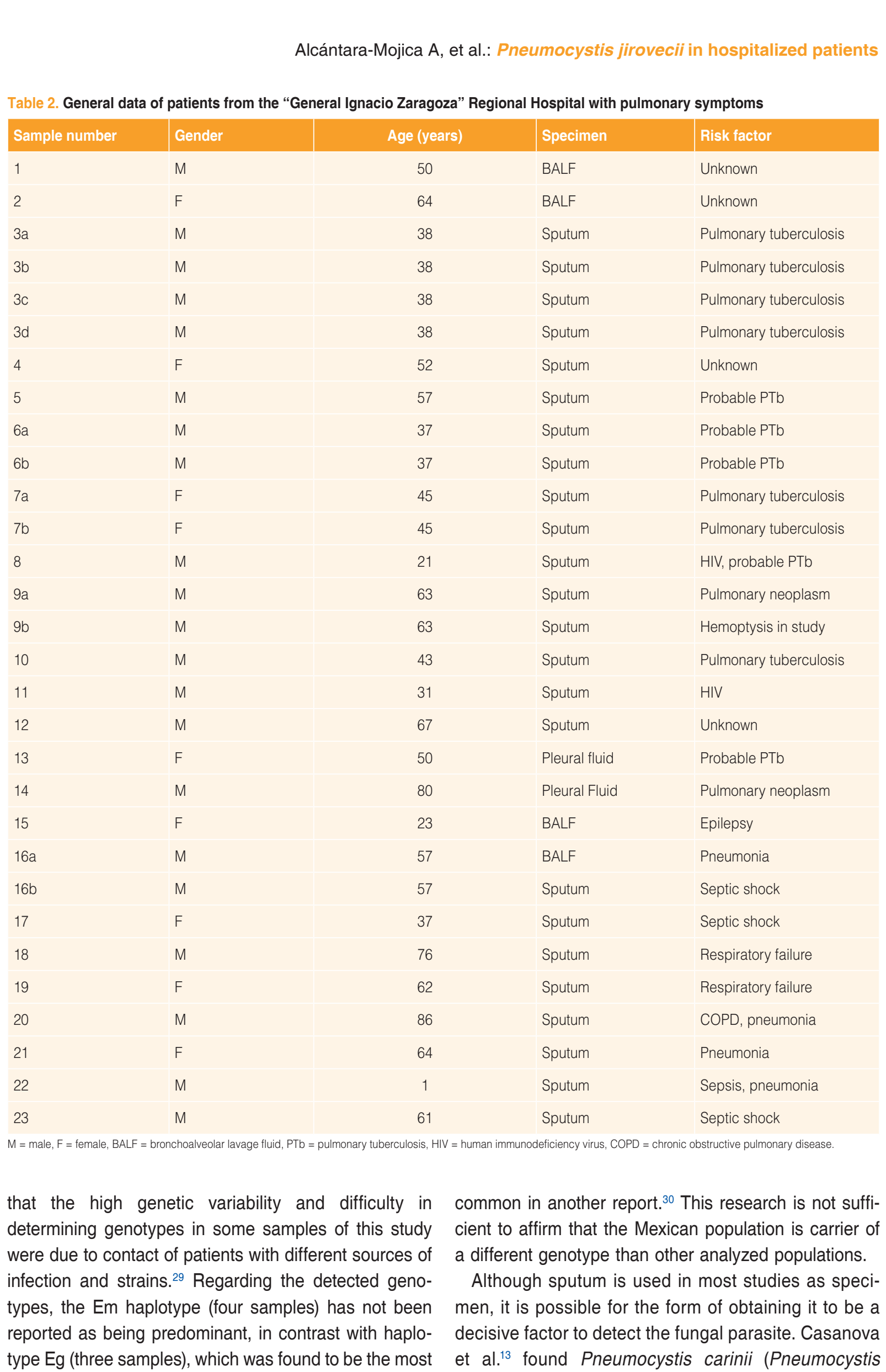


A

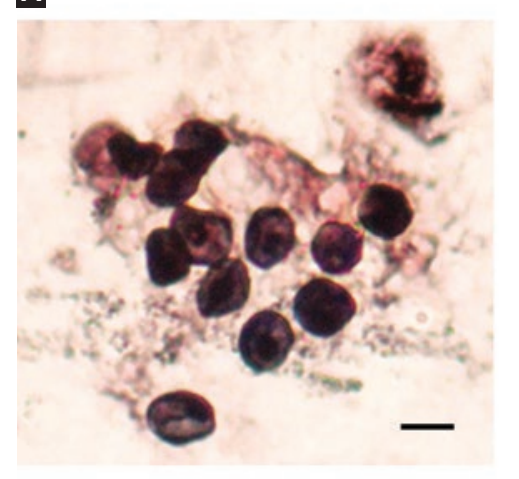

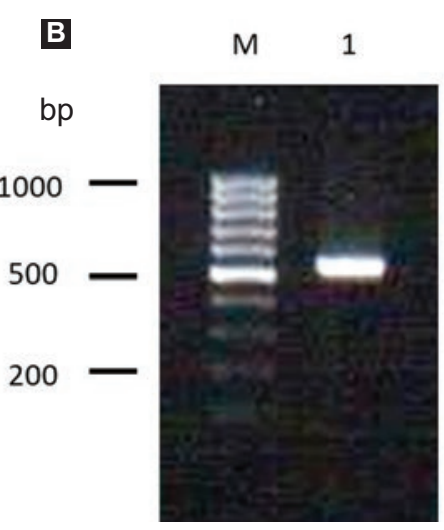

Figure 1. Study of the sample used as positive control (sample 1 of patients from the National Institute of Respiratory Diseases). A: GomoriGrocott staining, whereby Pneumocystis jirovecii typical cystic forms are observed (scale, $5 \mu \mathrm{m}$ ). B: Nested PCR product run on $1.5 \%$ agarose gel, stained with ethidium bromide. The 550-bp amplicon corresponds to Figure $1 \mathrm{~A}$ sample. $M=100$-bp molecular weight marker.

A

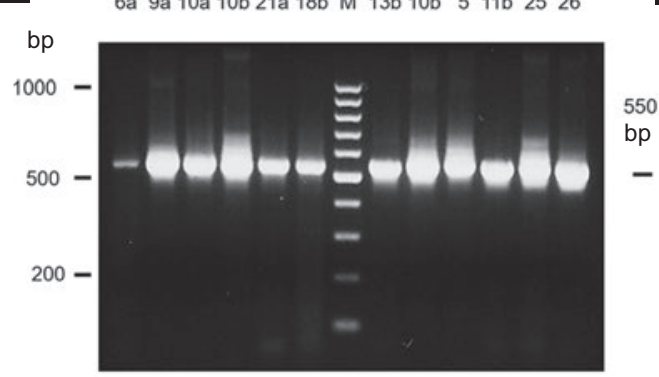

B

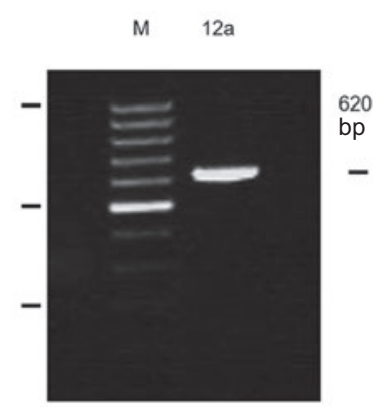

Figure 2. Pneumocystis jirovecii ITS region amplicons. A: Samples that amplified a fragment of the expected size (550 bp). B: Samplethat amplified a larger-than-expected fragment (620 bp). M = 100-bp molecular weight marker. The numbers at the top indicate the sample number.

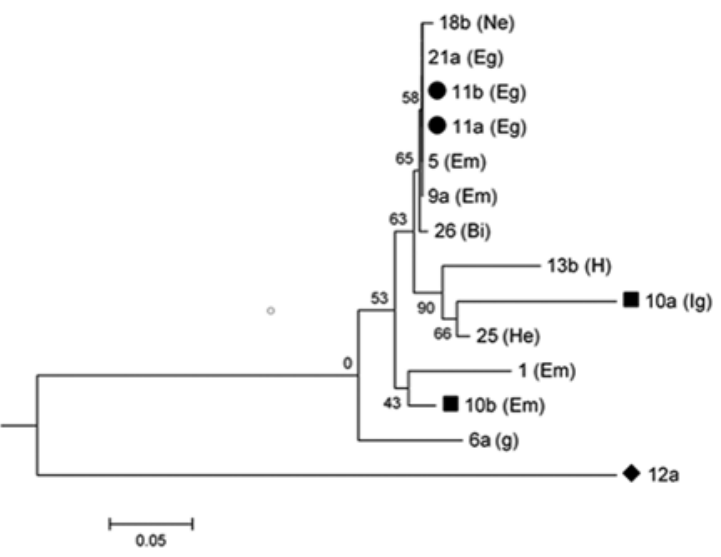

Figure 3. Phylogenetic tree, constructed with the neighb-or-joining method. The numbers correspond to each processed sample and the haplotype is indicated in parenthesis. Samples 10a and 10b, as well as $11 \mathrm{a}$ and $11 \mathrm{~b}$, correspond to a single patient, respectively. Cryptococcus neoformans was identified in sample 12a and was used as external control.

jirovecii) in $51 \%$ of 128 patients after obtaining sputum by induced expectoration and with Giemsa staining.

The HIV-infected population continues to be at high risk for developing PCP due to its low level of CD4 lymphocytes. ${ }^{31}$
PCP is a pathology that has a preponderant place in the population subjected to any immunosuppression factor. Globally, the annual prevalence of pheumonia due to Pneumocystis jirovecii is estimated to be 500,000 cases. ${ }^{32}$ To apply measures for the control of infectious diseases, in particular opportunistic infections such as PCP, it is necessary to know their epidemiological status at each country.

In this work, high positivity for Pneumocystis jirovecii and its genotypes was identified in HIV-positive Mexican patients through nested PCR targeting the gene of the ITS region. It is necessary to sukveil the Mexican population at risk for developing PCP by applying molecular procedures to determine with certainty the fungal load and, if possible, detecting strains resistant to therapeutically used medications in ofder to start specific treatment.

\section{Acknowledgements}

To Rocío López Álvarez, MSc, at "General Ignäcio Zaragoza" Regional Hospital, for her support in obtaining specimens. To the Research Coordination of 
the Faculty of Medicine of the National Autonomous University of Mexico, for the budget annually granted to Dr. Francisca Hernández Hernández.

\section{Source of funding}

This work was carried out with the budget granted by the Faculty of Medicine to Dr. Francisca Hernández Hernández as full-time " $\mathrm{C}$ " tenured professor.

\section{References}

1. Wang RJ, Miller RF, Huang L. Approach to fungal infections in human immunodeficiency virus-infected individuals: Pneumocystis and beyond. Clin Chest Med. 2017;38:465-477.

2. Calderón-Sandubete E, De Armas-Rodríguez Y, Capó-De Paz V. Pneumocystis jirovecii: cien años de historia. Rev Cubana Med Trop. 2011;63:97-116

3. Vera A, Pinochet R, Villamizar G, Cancino C, Henríquez L, Cabib C. Ventilación mecánica en pacientes $\mathrm{VIH}+$ en falla respiratoria aguda. Experiencia de una Unidad de Cuidados Intensivos de reciente creación. Rev Chil Med Intensiva. 2006;21:67-72.

4. Usha M, Rakshitha HB, Avnika J, Aneesha A, Sharon R. Morphological spectrum of fungal infections: a retrospective study. Int J Med Sci Public Health. 2016;5:1673-1677

5. López-Martínez R, Méndez-Tovar LJ, Hernández-Hernández F, Castañón-Olivares LR. Micología médica. México: Trillas; 2012.

6. Durand-Joly I, Chabé M, Soula F, Delhaes L, Camus D, Dei-Cas E. Molecular diagnosis of pneumocystis pneumonia. FEMS Immunol Med Microbiol. 2005:45:405-410.

7. Das S, Deb B. DNA barcoding of fungi using ribosomal ITS marker for genetic diversity analysis: a review. Int J Pure App Biosci. 2015;3 160-167.

8. Rodríguez-Tovar A, Xoconostle-Cázares B, Valdés M. Ecología molecular de los hongos ectomicorrízicos. Rev Fitotec Mex. 2004;27:267-278.

9. Lee CH, Helweg-Larsen J, Tang X, Jin S, Li B, Bartlett MS, et al. Update on Pneumocystis carinii f. sp. hominis typing based on nucleotide sequence variations in internal transcribed spacer regions of rRNA genes. J Clin Microbiol. 1998;36:734-741.

10. Miller RF, Lindley AR, Ambrose HE, Malin AS, Wakefield AE. Genotypes of Pneumocystis jirovecii isolates obtained in Harare, Zimbabwe, and London, United Kingdom. Antimicrob Agents Chemother. 2003;47: 3979-3981.

11. Wissmann G, Morilla R, Friaza V, Calderón E, Varela JM. El ser humano como reservorio de Pneumocystis. Enferm Infecc Microbiol Clin. 2010;28:38-43

12. Schmiedel Y, Zimmerli S. Common invasive fungal diseases: an overview of invasive candidiasis, aspergillosis, cryptococcosis, and Pneumocystis pneumonia. Swiss Med Wkly. 2016;146:w14281.

13. Casanova-Cardiel LJ, Barriga-Angulo G, Ruiz-Ordaz I, Fuentes-Allen JL. Frecuencia de Pneumocystis carinii en 128 pacientes con síndrome de inmunodeficiencia adquirida y neumonía intersticial. Diagnóstico mediante expectoración inducida. Rev Med Inst Mex Seg Soc. 1992;30:191-194.
14. García-Sancho MC, Pérez-González LE, Franco-Marina F, Reyes-Terân G. Infecciones oportunistas pulmonares en pacientes con infección por elvirus de la inmunodeficiencia humana del Instituto Nacional de Enfermedades Respiratorias 1991-2001. Rev Inst Nal Enf Resp Mex. 2003;16:6-10.

15. Lu JJ, Bartlett MS, Shaw MM, Queener SF, Smith JW, Ortiz-Rivera M, et al. Typing of pneumocystis carinii strains that infect humans base on nucleotide sequence variations of internal transcribed spacers of $\mathrm{R} N \mathrm{~N}$ genes. J Clin Microbiol. 1994;32:2904-2912.

16. Sanger F, Nicklen S, Coulson AR. DNA sequencing with chain-terminating inhibitors. Proc Natl Acad Sci USA. 1977;74:5463-5467.

17. Tamura K, Stecher G, Peterson D, Filipski A, Kumar S. Mega 6. Pnolecular evolutionary genetics analysis version 6.0. Mol Biol Evol. 2013;30:2725-2729.

18. Lu JJ, Chen CH, Bartlett MS, Smith JW, Lee CH. Comparison of six different PCR methods for detection of Pneumocystis carinii. $J$ Clin Microbiol. 1995;33:2785-2788.

19. Atzori C, Angeli E, Agostoni F, Mainini A, Micheli V, Cargnel A. Biomolecular techniques to detect Pneumocystis carinii f. sp. hominis pneumonia in patients with acquired inmunodeficiency syndrome. Int J Infect Dis. 1998-1999;3:76-81.

20. Álvarez-Martínez MJ, Miró JM, Valls ME, Moreno A, Rivas PV, Solé M, et al. Sensitivity and specificity of nested and real-time PCR in the detection of Pneumocystis jirovecii in clinical specimens. Diagn Microbiol Infect Dis. 2006;56:153-160.

21. Gupta R, Mirdha BR, Guleria R, Mohan A, Kabra SK, Kumar L, ',êt al. Use of different primer directed sequence amplification by polymerase chain reaction for identification of Pneumocystis jirovecii in clinica-samples. Indian J Chest Dis Allied Sci. 2008;50:321-327.

22. Pereira RM, Müller AL, Zimerman RA, Antunes DB, Zinn VF, Friaza V, et al. High prevalence of Pneumocystis jirovecii colonization among HIV-positive patients in southern Brazil. Med Mycol. 2014;52:804;809.

23. Lundgren $B$, Wakefield AE. PCR for detecting Pneumocystis carinii in clinical or environmental samples. FEMS Immunol Med Microbiol. 1998:22:97101.

24. Sheikholeslami MF, Sadraei J, Farnia P, Forozandeh-Moghadam M, Emadi-Kochak H. Co-infection of Mycobacterium tuberculosis and Bneumocystis jirovecii in the Iranian patients with human immunodeficiency virus. Jundishapur J Microbiol. 2015;8:e17254.

25. Medrano FJ, Montes-Cano MA, Conde M, De la Horra C, Respaldizza N, Gasch A, et al. Pneumocystis jirovecii in general population. Emerg Tnfect Dis. 2005;11:245-250.

26. Vargas SL, Hughes WT, Santolaya ME, Ulloa AV, Ponce CA, Gäbrera CE, et al. Search for primary infection by Pneumocystis carinii in a cohort of normal healthy infants. Clin Infect Dis. 2001;32:855-86

27. Skolnik K, Huston S, Mody CH. Cryptococcal lung infections. Clin Ē $\bar{C}$ est Med. 2017;38:451-464

28. Tsolaki AG, Miller RF, Underwood AP, Banerji S, Wakefield AE Genetic diversity at the internal transcribed spacer regions of the rRNA operon among isolates of Pneumocystis carinii from AIDS patients with reaurrent pneumonia. J Infect Dis. 1996;174:141-156.

29. Sokulska M, Kicia M, Wesolowska M, Piesiak P, Kowal A, Lobo ML et al. Genotyping of Pneumocystis jirovecii in colonized patients with various pulmonary diseases. Med Mycol. 2018;56:809-815.

30. Beser J, Botero-Kleiven S, Lebbad M, Hagblom P, Fernandez V. Âlimited number of ITS haplotypes defines the diversity of Pneumocystis jirovecii strains in Sweden. Infect Genet Evol. 2011;11:948-954.

31. Villasís-Keever A, Rangel-Frausto MS, Ruiz-Palacios G, Ponce de León-Rosales S. Clinical manifestations and survival trends during the first 12 years of the AIDS epidemic in Mexico. Arch Med Res. 2001;32:62-65.

32. Bongomin F, Gago S, Oladele RO, Denning DW. Global and multi-national prevalence of fungal diseases-estimate precision. J Fungi (Basel). 2017;3:57. 